\title{
Patterned Vision Causes CRE-Mediated Gene Expression in the Visual Cortex through PKA and ERK
}

\author{
Laura Cancedda, ${ }^{2 *}$ Elena Putignano, ${ }^{2 *}$ Soren Impey, ${ }^{3}$ Lamberto Maffei, ${ }^{1,2}$ Gian Michele Ratto, ${ }^{1}$ and \\ Tommaso Pizzorusso ${ }^{1,2}$ \\ ${ }^{1}$ Institute of Neuroscience of Consiglio Nazionale delle Ricerche, 56100 Pisa, Italy, ${ }^{2}$ Scuola Normale Superiore, 56100 Pisa, Italy, and ${ }^{3}$ Vollum Institute, \\ Oregon Health Sciences University, Portland, Oregon 97201-3098
}

\begin{abstract}
Normal visual experience during postnatal development is necessary for the maturation of visual cortical circuits and acts through molecular mechanisms that are still poorly understood. Recently, it has been shown that ERK (extracellular signal-regulated kinase) $1 / 2$, protein kinase A (PKA), and CREB (cAMP response element-binding protein) are crucial factors for experience-dependent development of the visual cortex, but very little is known about the role of visual experience in their activation. Here, we show that visual stimulation after a brief period of dark rearing caused a transient ERK activation in the visual cortex. Visually induced ERK activation occurred primarily in excitatory neurons of layers II-III and VI and was prevented by binocular lid suture. ERK phosphorylation was strongly reduced by cortical infusion with the cAMP-PKA inhibitor Rp-8-Cl-cAMPS, thus establishing a link between PKA and ERK activation.

To analyze the downstream consequences of ERK and PKA signaling, we studied the action of visual stimulation on transcription of genes controlled by CREB in transgenic mice carrying the LacZ reporter gene under the control of the CRE (cAMP response element) promoter. Visual stimulation triggered a prolonged episode of CRE-mediated gene expression in the visual cortex that was suppressed by infusion with the ERK inhibitor U0126. Cortical administration of Rp-8-Cl-cAMPS attenuated the experience-dependent activation of CRE-mediated gene transcription. These results show that ERK phosphorylation in visual cortical neurons represents a molecular readout of patterned visual stimuli and that visual activation of ERK involves the cAMP-PKA system. Finally, because CRE-mediated gene expression was totally dependent on ERK activation, we suggest that PKA action on CRE-mediated gene expression is mediated by ERK.
\end{abstract}

Key words: visual cortex; ERK; CREB; PKA; plasticity; visual stimulation

\section{Introduction}

The visual system reaches its mature form during a critical period of early postnatal development, in which electrical activity elicited by vision of spatial patterns has an essential role in sculpting cortical circuitry. The role of visual experience is highlighted by the effects of the suture of the eyelids of one eye (monocular deprivation). In this condition, vision of patterned stimuli through the sutured eye is impaired. As a consequence, cortical cells that are normally driven by both eyes become responsive almost exclusively to the nondeprived eye (Wiesel and Hubel, 1965). Notwithstanding 40 years of study of experiencedependent plasticity of the visual cortex, little is known about the intracellular mechanisms that convert patterned vision into modification of cortical circuits. Although recent experiments have demonstrated the implication in these processes of the three signaling molecules, ERK (extracellular signal-regulated kinase),

\footnotetext{
Received April 2, 2003; revised May 12, 2003; accepted May 16, 2003.

This work was supported by Ministero dell'Istruzione, dell'Università e della Ricerca COFIN 2001 and 2002, Consiglio Nazionale delle Ricerche Project SP-5, Progetto Strategico Neuroscienze Consiglio Nazionale delle Ricerche, and Fondo per gli Investimenti della Ricerca Projects RBNE019J7C_004 and RBNE01RZH4_002.

*L.C. and E.P. contributed equally to this work.

Correspondence should be addressed to Gian Michele Ratto, Institute of Neuroscience of Consiglio Nazionale delle Ricerche, Via Moruzzi 1, 56100 Pisa, Italy. E-mail: gimmi@in.pi.cnr.it.

Copyright $\odot 2003$ Society for Neuroscience $\quad$ 0270-6474/03/237012-09\$15.00/0
}

protein kinase A (PKA), and CREB (cAMP response elementbinding protein), the lack of knowledge on the signaling pathways, activated by patterned visual experience in cortical neurons, precludes the unification of the information in a comprehensive scheme that designs the cause-effect relationship between visually induced electrical activity, PKA, ERK, and CRE (cAMP response element)-mediated gene expression. Several studies have analyzed the interactions between these factors primarily in the in vitro system; however, the transferal of notions on signaling gathered in vitro to the behaving animal is not straightforward. Indeed, activity-dependent signaling is affected critically by the cellular context, characteristics of the in vitro model, and method of stimulation. For example, the picture of the relationship between PKA and CRE-mediated gene expression that emerges from in vitro studies is very variegated. PKA can act on CREB independently of ERK (Dash et al., 1991), or it can converge on ERK in a positive (Impey et al., 1998; Roberson et al., 1999) or negative (Grewal et al., 1999) way, allowing different partially incompatible pathways. To unravel the links between these factors in vivo, we analyzed ERK phosphorylation and CREmediated gene expression after patterned visual stimulation in animals treated with ERK and PKA inhibitors. We found that ERK phosphorylation in visual cortical neurons represents a molecular readout of patterned visual stimuli that is necessary for the 
Table 1. Percentage of cases expressing transgene on the total of heterozygous CRE-LacZ mice

\begin{tabular}{llll}
\hline & $\begin{array}{l}\text { Heterozygous } \\
\text { mice }\end{array}$ & $\begin{array}{l}\text { Cases expressing } \\
\text { transgene }\end{array}$ & Percentage \\
\hline Nor & 14 & 6 & $43 \%$ \\
DR & 11 & 4 & $36 \%$ \\
DR+light & 12 & 8 & $67 \%$ \\
DR+light+U0126 & 13 & 4 & $31 \%$ \\
DR+light+ vehicle & 10 & 4 & $40 \%$ \\
DR+light+Rp-8-Cl-cAMPS & 5 & 4 & $80 \%$ \\
Binocular deprivation & 9 & 3 & $33 \%$ \\
Monocular deprivation+U0126 & 8 & 3 & $37 \%$ \\
Total & 82 & 36 & $44 \%$ \\
\hline
\end{tabular}

subsequent activation of CRE-mediated gene expression. PKA inhibition affected CRE-mediated gene expression but also reduced experience-dependent ERK activation, suggesting that its action on CRE-mediated gene expression is mediated by ERK.

\section{Materials and Methods}

Animals were used in accordance with protocols approved by the Italian Minister for Scientific Research. Control animals were exposed to a $12 \mathrm{hr}$ light/dark cycle, with the light phase beginning at 6:00 A.M. All animals were killed at the same time of the day, between 8:00 and 9:00 A.M. Manipulations during dark rearing were performed in complete darkness using infrared viewers.

Animal treatment. A group of animals was implanted with osmotic minipumps ( $0.5 \mu \mathrm{l} / \mathrm{hr}$; ALZET 1007D; Alzet, Palo Alto, CA) connected to a cannula (gauge 30; model 1007D; Alzet) via PVC tubing at a location 4 $\mathrm{mm}$ anterior and $3 \mathrm{~mm}$ lateral to $\lambda$ for mice, and $5 \mathrm{~mm}$ anterior and 4 $\mathrm{mm}$ lateral for rats. Minipumps were filled with U0126 (250 $\mu$ M; Promega, Madison, WI), Rp-8-Cl-cAMPS (20 mm; Biolog), or DMSO (1\%).

Immunohistochemistry. A total of 33 Long-Evans Hooded rats and 16 C57BL6/J mice were used to study ERK activation. We used animals inside the critical period ranging from postnatal day (P) 23-P27. Transcardial perfusion was executed with ice-cold $4 \%$ paraformaldehyde in $0.1 \mathrm{~m}$ TBS and $1 \mathrm{~mm}$ sodium orthovanadate, $\mathrm{pH} 7.4$ (TBSV). Brains were quickly removed and cryoprotected in $30 \%$ sucrose overnight and then $35 \mu \mathrm{m}$ coronal sections were cut on cryostat and processed for phosphorylated ERK (pERK) immunohistochemistry. Free-floating sections were subjected to a $1 \mathrm{hr}$ block (TBSV containing 10\% BSA and 0.3\% Triton X-100) followed by incubation with pERK antibody (1:1000; Sigma, St. Louis, MO) (in TBSV containing 5\% BSA and $0.1 \%$ Triton X-100). The reaction was completed with biotinylated secondary antibody (1:200; Vector Laboratories, Burlingame, CA) followed by Extravidin-Cy3 (1: 1000; Sigma). For double immunostaining, GFAP (1:500; Dako, Carpinteria, CA), neuronal-specific nuclear protein (1:500; Chemicon, Temecula, CA), and GAD 67 (1:500; Chemicon) were added after the end of pERK immunohistochemistry. The reactions were then completed with Alexa 488-conjugated (1:400 for GFAP and NeuN; Molecular Probes, Eugene, OR) or fluorescein-conjugated secondary antibodies (1:300 for GAD67; Jackson ImmunoResearch, West Grove, PA). Slices were coded, and confocal images (Olympus FV-300; Olympus Optical, Melville, NY) of at least six representative fields for each animal were acquired blind. All sections were acquired in random order in a single session to minimize fluctuation in laser output and degradation of fluorescence. Images were analyzed through custom-made software to count positive neurons and measure their fluorescence intensity. The code was broken only at the end of the analysis process.

$X$-gal histochemistry. We used $82 \mathrm{CRE}-$ LacZ transgenic mice (Impey et al., 1996) as detailed in Table 1. Colony founders were bred with wildtype C57BL6/J mice. The transgene was maintained in heterozygous mice. Genotyping was performed by PCR. Animals were decapitated, and the brains were rapidly dissected and then submerged in ice-cold fixative (3\% paraformaldehyde, $0.1 \mathrm{~m}$ phosphate buffer) for $4 \mathrm{hr}$ on ice. X-gal histochemistry was described previously (Barth et al., 2000). After- ward, slices were stained with neutral red to visualize the cortical layers. Acquisition of at least five different fields for each animal was performed at the confocal microscope operating in transmitted light mode using the red line $(647 \mathrm{~nm})$ of an $\mathrm{Ar}-\mathrm{Kr}$ laser to maximize the contrast of the blue cells against the red background.

pERK activation in cultured neurons. Cultures were prepared from rat visual cortex (P1) as described previously (Pizzorusso et al., 2000). After pharmacological treatment, cells were fixed in ice-cold $4 \%$ paraformaldehyde in $0.1 \mathrm{M} \mathrm{TBSV}$ and treated for pERK histochemistry as described above.

\section{Results}

Experience-dependent activation of ERK and CRE-mediated gene expression in the visual cortex was measured at different times from the onset of an episode of visually driven activity. Such a visual stimulation was provided by exposing the animals to a normal visual environment after a brief period of complete darkness.

\section{Visual experience causes transient ERK phosphorylation in vivo}

Rats and mice that were within the critical period for ocular dominance plasticity (P23-P27) were placed in darkness for $3 \mathrm{~d}$. A group of control animals was anesthetized while still in complete darkness and immediately perfused. Three other experimental groups were perfused after exposure to normal visual environment for 5, 15, and $40 \mathrm{~min}$. Immunohistochemistry with an antibody that binds specifically to pERK was performed on slices from all experimental groups (Fig. 1). Visual stimulation caused a strong increase of the pERK signal in the visual cortex (Fig. $1 A$ ), as shown in representative fields of the superficial layers of the binocular visual cortex (Fig. $1 B$ ). pERK induction was expressed by both an augmented fluorescence and an increase in the number of positive cells. Quantification of data for each experimental group is shown in Figure 1C. In all experiments, image acquisition and data analysis were performed by an operator who was blind to the treatment. Visual stimulation induced a rapid increase of the number of pERK positive cells that was clearly discernible after $5 \mathrm{~min}$ of visual activity and peaked at $15 \mathrm{~min}$ [percentage, with respect to the dark-reared (Dr) control group kept in darkness: $190 \pm 21 \%$ rat, 5 min; $215 \pm 16 \%$ rat, 15 min; $228 \pm$ $18 \%$ mouse, $15 \mathrm{~min})$. This activation was transient because 40 min after the beginning of visual stimulation, the amount of pERK positive profiles returned to the baseline level held by the Dr group ( $92 \pm 25 \%$ rats; $70 \pm 20 \%$ mice). No significant difference in the temporal evolution of ERK activation was observed between rats and mice (Fig. $1 C$ ).

To characterize the populations of pERK-positive cells, we performed double immunostaining of cortical slices from the group exposed to light for $15 \mathrm{~min}$. Immunostaining for pERK and astrocytic marker GFAP showed no colocalization between these antigens (data not shown). The neuronal nature of pERKpositive cells was confirmed by double immunostaining with the neuronal marker NeuN and by a clear pyramidal morphology (Fig. $1 D$ ). Immunostaining for pERK and GAD 67 revealed that, in layers II-III, only $6 \%$ of the GAD 67-positive profiles are also positive to pERK (18 of 297) (Fig. $1 E$ ). The remaining pERKpositive cells (396) did not colocalize with GAD 67 and were therefore excitatory. In most cells, the pERK staining was rather uniformly distributed in the cytoplasm, nucleus, and proximal segment of primary dendrites (Fig. $1 D$ ). However, occasionally, cells with a low nuclear staining were observed (Fig. $1 E$ ), but their number did not correlate with the treatment and varied from 

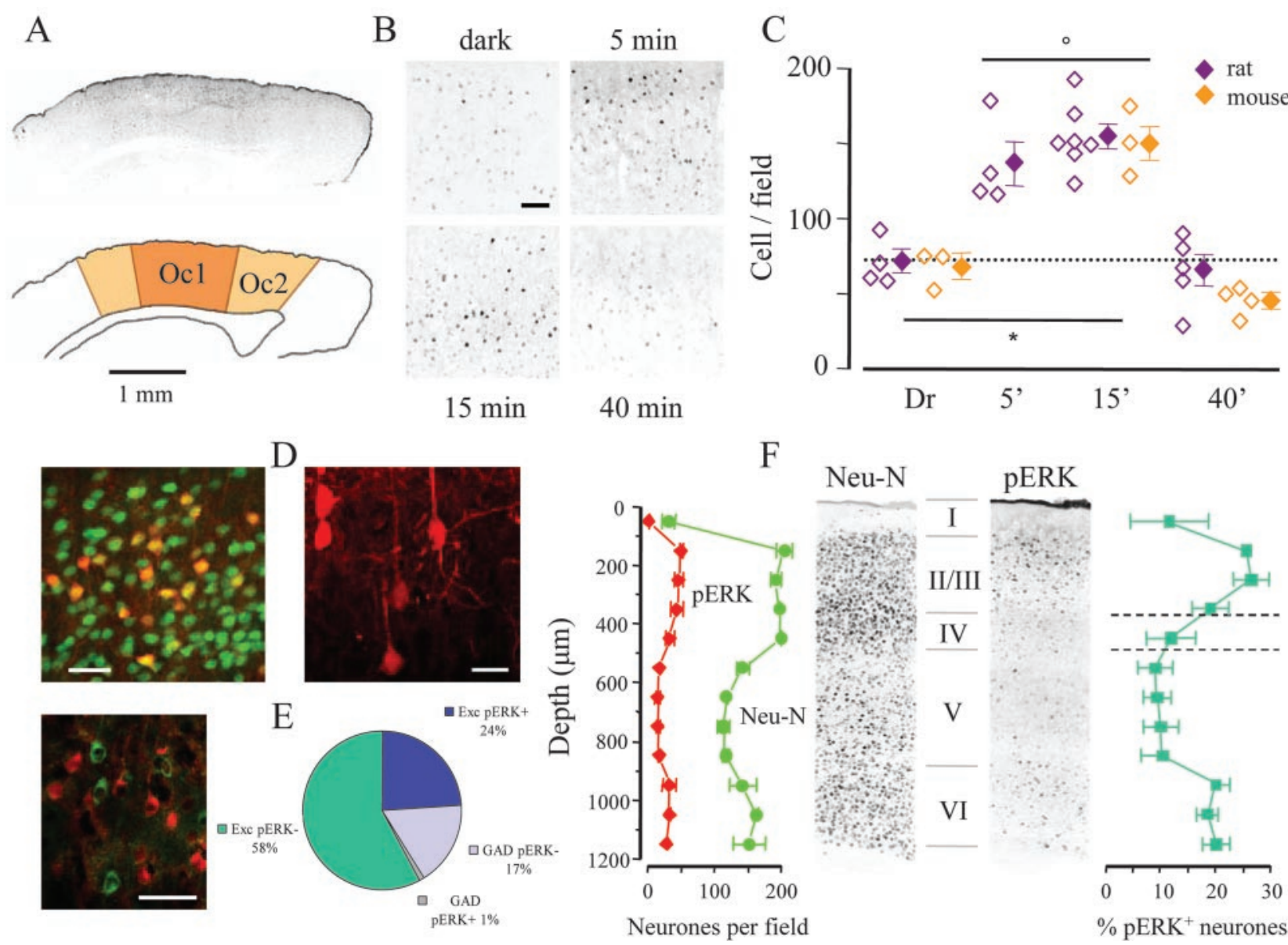

Figure 1. Visual experience induced ERK phosphorylation in the visual cortex after a $3 \mathrm{~d}$ period of obscurity during the critical period. $A$, pERK immunofluorescence of a transverse section of a mouse brain approximately $-3 \mathrm{~mm}$ from bregma, $15 \mathrm{~min}$ after return to light. Positive cells were concentrated in the primary $(0 \mathrm{c} 1)$ and secondary $(0 \mathrm{c} 2)$ visual cortices. $B$, Fields of layers III-III in rats exposed to light for the specified time. C, pERK-positive cells were counted in fields $\left(0.49 \mathrm{~mm}^{2}\right)$ centered on the binocular cortex. Open symbols show the average count for each animal and the average \pm SEM for each experimental group. Two-way ANOVA showed no effect of the species $(p=0.234)$ and a significant effect of the time $(p<0.001)$. The density of pERK-positive cells was significantly different from $\operatorname{Dr}$ at 5 and $15 \mathrm{~min}(p<0.05$ ) but not at $40 \mathrm{~min}$ ( $p>0.05$; Tukey tests). The horizontal bar with an asterisk indicates that the groups are statistically different, and the open circle indicates statistical identity. D, Left, Double immunostaining for pERK (red) and the neuronal marker NeuN (green). In layers II-III, 25\% of the neuronal population was pERK positive after $15 \mathrm{~min}$ of visual activity. Right, pERK-positive neurons had a characteristic pyramidal morphology. E, Immunostaining for pERK and GAD67 (green) shows that the vast majority of pERK-positive neurons was excitatory, as quantified in the pie diagram (three animals). $F$, Double immunostaining for NeuN and pERK shows that pERK-positive neurons were distributed primarily in the superficial layers of the cortex. Counting has been performed on a single optical section at the confocal microscope, dividing the cortex in bins of $100 \mu \mathrm{m}$ thick. Averages of counting on two slices were obtained from three separate rats. Identical results have been obtained in mice. Scale bars: $A, 1 \mathrm{~mm} ; B, 100 \mu \mathrm{m} ; D, 20 \mu \mathrm{m} ; E, 40 \mu \mathrm{m}$.

animal to animal, possibly reflecting differences in the preparation of the tissue for immunohistochemistry.

Neurons that were positive for pERK were unevenly distributed across the cortical layers. Sections of the primary visual cortex were processed for pERK and NeuN immunoreactivity, and cells positive for the two stainings were counted in $100 \mu \mathrm{m}$ thick bins along the cortical thickness (Fig. $1 F$ ). The fraction of pERKpositive cells, with respect to the total number of neurons, peaked in layers II-III, in which $\sim 25 \%$ of the total neuronal population was pERK positive, and peaked in layer VI. In contrast, the fraction of pERK-positive neurons was much lower in layers IV and V (Fig. $1 F)$.

Anesthesia is a condition that is known to impair many forms of plasticity; for example, repeated administrations of anesthetic prevent the effect of monocular deprivation (Rauschecker and Hahn, 1987). Because ERK acts as an encoder of visually driven activity, it is interesting to study the link between visual stimulation and ERK activation under anesthesia. Urethane anesthesia prevented ERK induction by light exposure (Fig. 2A). The dose used $(1.2 \mathrm{gm} / \mathrm{kg})$ is common for anesthetizing rodents during physiological recordings and does not suppress visually driven activity in the cortex. This inhibition is not caused by a direct effect of the anesthetic on the ERK pathway because urethane, administered to cultured visual cortical neurons at a concentration (10 $\mathrm{mm}$ ) similar to the plasma level attained during surgical anesthesia (Hara and Harris, 2002), did not interfere with ERK activation caused by $\mathrm{KCl}$-driven depolarization for $3 \mathrm{~min}$ (Fig. $2 B, C)$. These data demonstrate that ERK is rapidly and transiently activated by patterned visual experience in neurons of the rodent visual cortex.

\section{Visual experience induces CRE-mediated gene expression through ERK activation}

Next, we investigated whether ERK activation, induced by visual stimulation, was followed by CRE-mediated gene expression by using transgenic mice carrying the $L a c Z$ reporter gene under the control of a minimal promoter driven by five copies of the CRE promoter (Impey et al., 1996). Involvement of ERK in downstream gene transcription was assessed by using U0126, a selective inhibitor of the ERK kinase MEK (MAP kinase kinase). This 
A

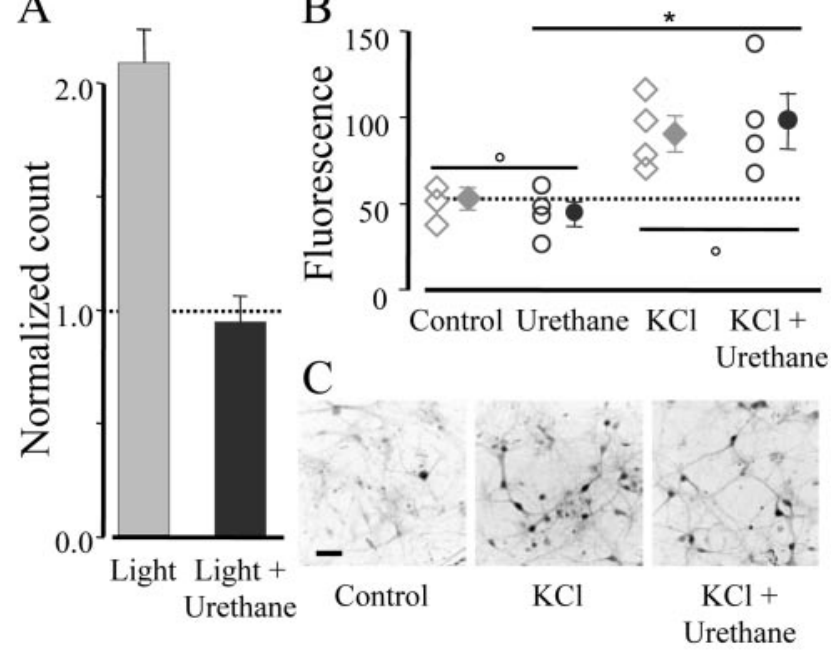

Figure 2. ERK phosphorylation induced by visual activity required wakefulness. A, Fifteen rats were kept in darkness for $3 \mathrm{~d}$ and then nine animals received an intraperitoneal injection of urethane $(n=5)$ or saline before being returned to light for $15 \mathrm{~min}$. The remaining six rats were kept in darkness and acted as controls. Anesthetized animals had a level of pERK phosphorylation comparable with the Dr controls (dotted line), whereas saline-injected animals had normal activation (one-way ANOVA; $p<0.01$; post hoc Tukey test; light plus urethane vs $\mathrm{Dr}, p>0.05$, and vs light, $p<0.05)$. $B$, An anesthetic concentration of urethane did not directly inhibit ERK phosphorylation. Cultured neurons from the visual cortex were processed for pERK immunostaining after a pulse of $90 \mathrm{~mm} \mathrm{KCl}$ in the presence of $10 \mathrm{~mm}$ urethane and under control conditions. Each symbol represents the average counting obtained from several fields acquired on each coverslip, and filled symbols indicate mean \pm SEM. One-way ANOVA $(p<0.05)$ followed by post hoc Student-Newman-Keuls test shows that $\mathrm{KCl}$ and $\mathrm{KCl}$ plus urethane did not differ between each other $(p>0.05)$ and were statistically different from saline or urethane $(p<0.05)$. Urethane, per se, did not affect pERK levels $(p>0.05)$. C, Fields showing $\mathrm{pERK}$ immunostaining in the indicated conditions. Scale bar, $50 \mu \mathrm{m}$.

inhibitor, which fully blocks ERK activation after presentation of a variety of stimuli (Roberson et al., 1999; Pizzorusso et al., 2000), was infused by osmotic minipumps to the cortex. U0126 infusion prevents the effects of monocular deprivation without altering either spontaneous or visually driven electrical activity of cortical neurons (Di Cristo et al., 2001).

$\beta$-galactosidase, the product of the $L a c Z$ gene, can be assayed by a histochemical reaction that produces a blue precipitate in cells in which CRE-mediated gene expression occurred. Because of the heterogeneous expression of $\mathrm{LacZ}$ in animals derived from the same founder (Impey et al., 1996; Pham et al., 1999; Barth et al., 2000), not all genotyped mice were included in the analysis. We examined brain sections cut from the occipital pole up to the parietal cortex of each genotyped CRE-LacZ mouse, and it was assigned to the LacZ-expressing group if we could detect at least one clearly stained neuron in these sections. The animals with these characteristics corresponded to $\sim 44 \%$ of the total number of processed animals (Table 1). Mice within the critical period (P23-P26) were divided in five experimental groups and treated as follows: the control group was kept in a normal light/dark cycle; a second group was killed at the end of a $3 \mathrm{~d}$ period of dark rearing without any exposure to light; the third group was dark reared for a similar duration and then exposed to a normal visual environment for $12 \mathrm{hr}$; and the fourth and fifth groups of mice were implanted with an osmotic minipump, delivering either U0126 $(250 \mu \mathrm{M})$ or the vehicle solution (1\% DMSO). After $3 \mathrm{~d}$ of dark rearing, these mice were exposed to light for $12 \mathrm{hr}$.

Visual stimulation activated CRE-mediated gene expression, as demonstrated by mere visual inspection of the processed brains (Fig. 3A). The visual cortex of the group that returned to light appeared blue against a clear background. Infusion of U0126 to one hemisphere completely prevented the expression of $\mathrm{LacZ}$ in the treated hemisphere but not in the contralateral cortex. Figure $3 B$ shows examples of $X$-gal staining from the different experimental groups.

The density of cells with $\beta$-gal activity in the visual cortex of each animal in the five experimental groups is shown in Figure $3 C$. Dark rearing induced a significant reduction in the number of stained cells, compared with the control group that was kept in a normal light/dark cycle. Twelve hours of visual experience after $3 \mathrm{~d}$ of darkness caused a marked induction of LacZ expression, as indicated by a more than threefold increase in the density of $\mathrm{X}$-gal-positive cells. The induction of CRE-mediated transcription by visual experience was blocked in cortices infused with U0126. Normal induction was observed in cortices treated with vehicle.

Recent experiments observe a high density of LacZ-positive cells in the visual cortex contralateral to the nondeprived eye of monocularly deprived CRE-LacZ mice (Pham et al., 1999). By comparing the number of positive cells in monocularly deprived mice treated with U0126 in the cortex contralateral to the nondeprived eye with that of monocularly deprived control mice, we found that ERK inhibition strongly affected LacZ expression also after monocular deprivation (U0126, $9.9 \pm 2.3$ cells per field; control, $113.5 \pm 36.8$ cells per field; $t$ test; $p<0.05$ ). These data demonstrate that visual experience induces CRE-mediated gene expression in visual cortical neurons by activating intracellular signaling pathways that require ERK phosphorylation.

\section{Kinetics of CRE-mediated gene expression}

Because the peak of ERK phosphorylation occurred between 5 and 40 min after the return of Dr animals to normal visual environment, we asked whether we could detect any sign of CREmediated gene expression at a shorter time than $12 \mathrm{hr}$. A group of Dr mice was killed $2 \mathrm{hr}$ after returning to light. At this time, the density of X-gal-positive cells was not significantly different from the density observed after $12 \mathrm{hr}$ of exposure to light. Because the turnover of $\beta$-gal is $\sim 8 \mathrm{hr}$ (Pham et al., 1999), we can infer that in the presence of normal vision, CRE-mediated gene expression is maintained for at least several hours (Fig. 3D).

Furthermore, because pERK peaks within $30 \mathrm{~min}$ from induction, we wondered whether exposure to normal visual environment for this duration would be sufficient to drive gene expression. Two groups of Dr mice received the following treatments. The first group was returned to light for $30 \mathrm{~min}$ and then returned to complete darkness for an additional $90 \mathrm{~min}$ period (Fig. 3E, $\left.30^{\prime}\right)$. This additional period of dark rearing restricted visual experience to the time when ERK activation peaked and allowed a subsequent lag period for $\beta$-gal synthesis. The second experimental group was treated equally but was returned to darkness for $11 \mathrm{hr}$ and $30 \mathrm{~min}$ (Fig. 3E, 30'-12 hr) before being killed.

The brief episode of light exposure evoked a level of CREmediated gene expression that, $2 \mathrm{hr}$ after the beginning of treatment (30 min of light plus 90 min of darkness), was identical to the level caused by continuous exposure to light for the same time. This indicates that $30 \mathrm{~min}$ of visual experience was sufficient to induce CRE-mediated gene expression, which, given the kinetics of ERK activation, is consistent with a causal role for ERK in experience-dependent CRE-mediated gene expression. However, the maintenance of $L a c Z$ expression was impaired by the return to darkness. Indeed, after $11.5 \mathrm{hr}$ of obscurity, the density of positive cells returned almost to the Dr level. Another spatio- 

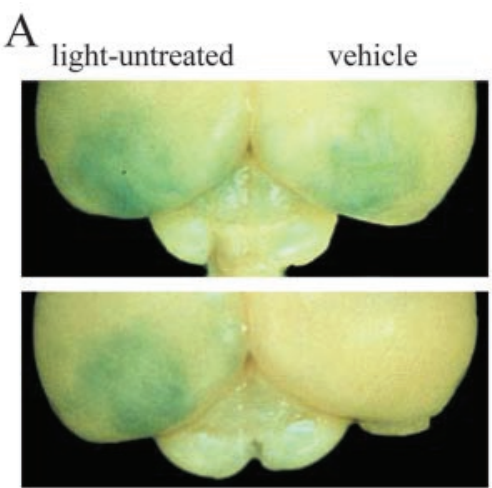

light-untreated
U0126
B

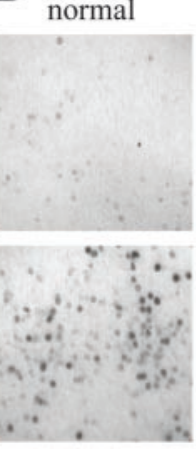

$12 \mathrm{hr}$ light dark

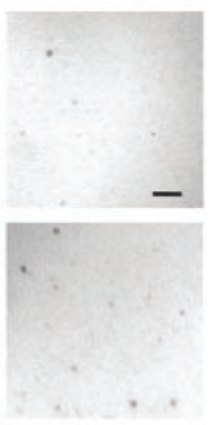

light+U0126

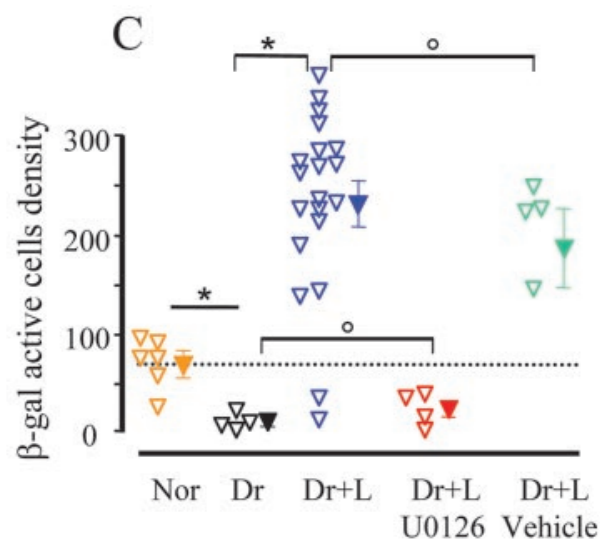

$\mathrm{E}$
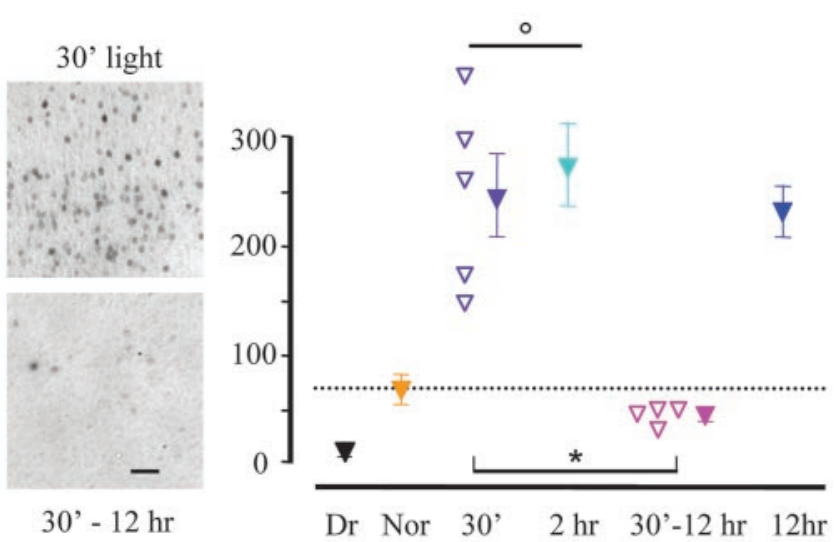

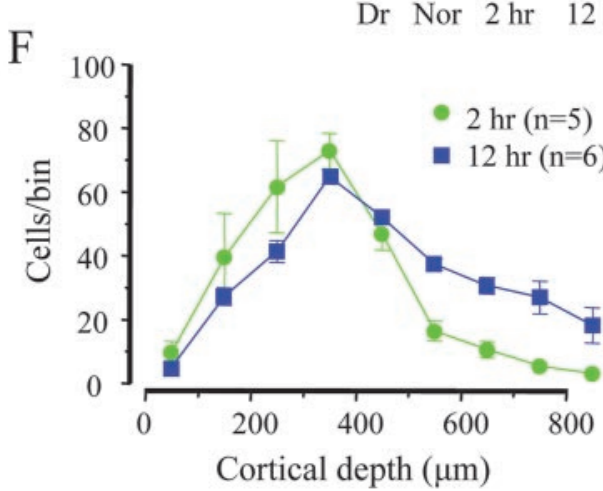

Figure 3. Visual experience after a $3 \mathrm{~d}$ period of darkness caused CRE-mediated gene expression to be dependent on ERK activation. $A$, Brains that reacted for X-gal histochemistry show that the visual cortex was densely populated with positive neurons. Treatment with the ERK kinase inhibitor U0126 completely suppressed CRE-mediated gene expression in the treated but not in the control hemisphere. B, Fields from superficial layers of the visual cortex in the indicated conditions. C, Quantification of the density of positive cells ( $1 \mathrm{~mm}^{2}$ fields). Dr has significantly less positive cells than mice kept in a normal visual environment (Nor) ( $t$ test; $p<0.01$ ). Exposure to light significantly increased the number of positive cells, an effect completely prevented by U0126 but not by its vehicle (one-way ANOVA; $p<0.01$; post hoc Tukey test; $p<0.05$ ). The $\mathrm{Dr}$ plus light ( $\mathrm{Dr}+\mathrm{L}$ ) group was composed of eight mice plus an additional 12 cortices from the control side of the minipump experiments. $D$, Two and $12 \mathrm{hr}$ of visual experience equally activated CRE-mediated gene expression (one-way ANOVA; $p<0.01$; post hoc Tukey test; $p<0.01$ ). $E$, Thirty minutes of visual experience followed by $90 \mathrm{~min}$ of darkness was sufficient to trigger (RE-mediated gene expression to a level not significantly different from visual stimulation for the same period of time ( $t$ test; $p=0.64)$. Gene expression was not maintained in the absence of visual experience, because if the $30 \mathrm{~min}$ stimulation was followed by $11.5 \mathrm{hr}$ of darkness, the number of X-gal-positive cells was strongly decreased $(t$ test; $p<0.01)$. $F$, Distribution of X-gal-positive cells throughout the cortical depth. Scale bars, $50 \mu \mathrm{m}$. Asterisks and circles indicate groups that are statistically different or identical, respectively. Open symbols indicate data from a single animal; filled symbols are the averages.

temporal aspect of visual experience-dependent gene expression is reflected by the distribution of positive cells across the thickness of the visual cortex (Fig. $3 F$ ). Measures of cell density (in 100 $\mu \mathrm{m}$ thick bins) in the function of cortical depth show that $2 \mathrm{hr}$ after return to light, the distribution of X-gal-positive cells is maximum toward the surface of the cortex, whereas $10 \mathrm{hr}$ later, more cells are recruited in the deeper cortical layers. These experiments showed that a 30 min exposure to normal visual environment is sufficient to activate CRE-mediated gene expression, and that continuous exposure to normal environment is required for prolonged expression.

\section{Light-induced ERK activation and CRE-mediated gene expression require patterned visual stimulation}

The effects of visual deprivations are thought to be attributable to the lack of patterned visual stimulation through the deprived eye(s). The loss of cortical response to the deprived eye that is typically caused by unilateral suture of the eyelids is also present 

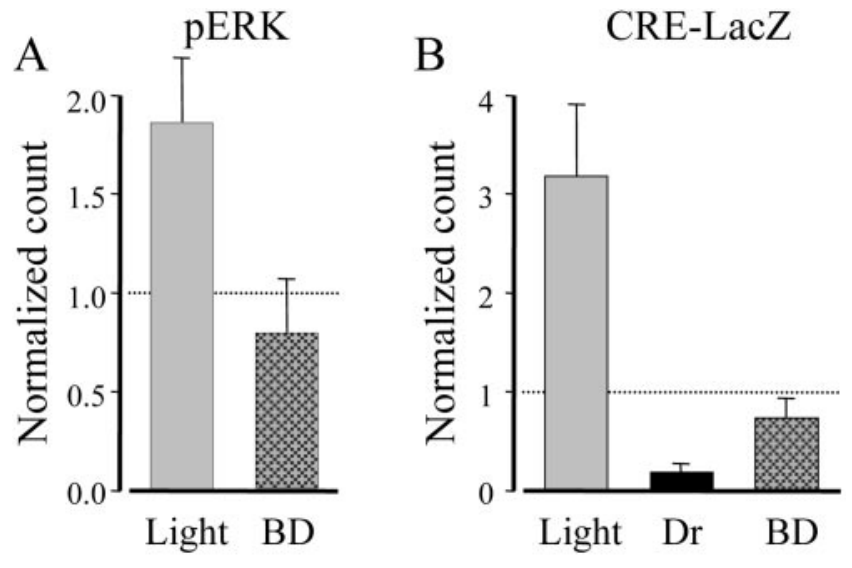

Figure 4. Pattern vision was required for ERK phosphorylation and CRE-mediated gene expression. $A$, Three rats in the critical period were deprived of pattern vision by binocular deprivation (BD). After $3 \mathrm{~d}$ in darkness, they were returned to light for $15 \mathrm{~min}$. Two additional rats were returned to light with open eyelids, and four rats remained in darkness and acted as controls. PERK-positive cell counting is expressed as a fraction of control. BD completely suppressed $p E R K$ activation after returning to light (Kruskal-Wallis one-way ANOVA on ranks, $p=$ 0.004; post hoc Dunn's method BD vs light, $p<0.05$, and vs Dr, $p>0.05$ ). B, A similar protocol of $B D$ and dark rearing was applied to the CRE-LacZ mice (see Table 1). Cell densities are shown normalized to the density of control mice that were kept in a normal light/dark cycle. BD drastically reduced the gene expression $12 \mathrm{hr}$ after returning to light (one-way ANOVA, $p<$ 0.001; post hoc Tukey test, BD vs light, $p<0.05$, vs Dr and norm, $p>0.05$ ).

when one eye is deprived of patterned visual stimuli by unilateral blur (Christen and Mower, 1987; Movshon et al., 1987). At the cellular level, the lack of patterned visual stimulation likely results in depriving cortical neurons of the high-frequency trains of action potentials relevant for plasticity. We asked whether the different patterns of visual stimulation that occur in normal animals and animals with binocular lid suture can have a molecular readout, in terms of ERK phosphorylation and CRE-mediated gene expression.

A group of rats received a bilateral eyelid suture before the beginning of the $3 \mathrm{~d}$ period of dark rearing and were exposed to light for $15 \mathrm{~min}$ before being killed. As shown in Figure $4 \mathrm{~A}$, binocular deprivation prevented ERK activation by visual experience. Consistently, $12 \mathrm{hr}$ after the end of dark rearing, X-gal staining in binocularly deprived CRE-LacZ mice was more than threefold lower than in nondeprived animals exposed to light for the same period of time (Fig. $4 B$ ).

\section{cAMP signaling is required for CRE-mediated gene expression}

Inhibition of cAMP signaling by Rp-8-Cl-cAMPS blocks ocular dominance plasticity induced by monocular deprivation (Beaver et al., 2001). In vitro experiments have shown that PKA can act on CRE-mediated gene expression through the ERK pathway (Impey et al., 1998); we asked whether a similar dependency might be present in the visual cortex in vivo. A group of CRE-LacZ mice was implanted with osmotic minipumps containing the cAMP inhibitory analog Rp-8-Cl-cAMPS (20 mM) before the beginning of the darkness period. Minipumps filled with the vehicle were used as controls. Animals were processed after $12 \mathrm{hr}$ of exposure to normal visual environment. We found that inhibition of cAMP signaling strongly reduced the induction of CRE-mediated gene expression by visual experience (Fig. 5A). The cAMP pathway also contributed to the visually induced activation of ERK. Figure $5 B$ shows that cortices implanted with osmotic minipumps containing Rp-8-Cl-cAMPS showed only $43 \%$ of the

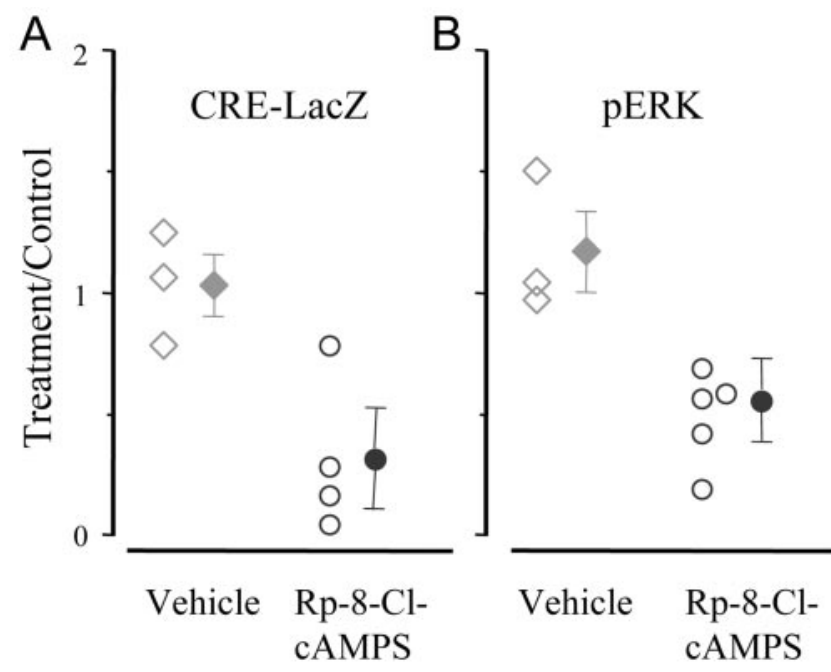

Figure 5. Inhibition of CAMP signaling reduced visually driven CRE-mediated gene expression and ERK phosphorylation. $A$, CRE-LacZ mice were implanted with osmotic minipumps that delivered either vehicle or Rp-8-Cl-cAMPS to the visual cortex. After 3 din darkness, the animals were returned to light for $12 \mathrm{hr}$ before being killed and histochemistry. The density of X-galpositive cells in Rp-8-Cl-cAMPS-treated cortices was reduced with respect to the untreated cortex of the same animal (paired $t$ test; $p<0.05$ ) but was increased with respect to $\mathrm{Dr}$ ( $t$ test; $p<0.05$ ). Vehicle treatment was ineffective (paired $t$ test; $p>0.05$ ). $B$, Ratio of $p$ ERK-positive cells in the treated vs untreated cortex of eight rats implanted with osmotic minipumps as above. After $3 \mathrm{~d}$ in darkness, the animals were returned to light for $15 \mathrm{~min}$ before being killed. The density of pERK-positive neurons was clearly reduced by the infusion of Rp-8-Cl-cAMPS (paired $t$ test; untreated cortex vs treated cortex of the same animal; $p<0.05$ ), although it was increased with respect to $\mathrm{Dr}$ rats $(t$ test; $p<0.05$ ). The treatment with vehicle did not affect ERK activation (paired $t$ test; $p>0.05$ ). Open symbols indicate data from each animal; filled symbols are the group averages.

visually dependent ERK activation present in cortices treated with vehicle. The inhibition of the CAMP-PKA pathway did not appear to cause a block of pERK translocation into the nucleus, because we did not observe any increase in the percentage of cells with low pERK nuclear staining compared with control (control, $10.3 \pm 0.9 \%$; Rp-8-Cl-cAMPS, $10.2 \pm 2.6 \%)$. We conclude that CAMP-PKA is involved in the signaling process that mediates the action of visual experience on ERK activation and CRE-mediated gene expression.

\section{Discussion}

In this study, we demonstrate that ERK, cAMP-PKA, and CREB are part of a single experience-dependent transduction pathway, thus unifying into a single interpretative framework (Fig. 6), recent results that have demonstrated the necessity of these factors for ocular dominance plasticity (Beaver et al., 2001; Di Cristo et al., 2001; Mower et al., 2002). Specifically, activation of the ERK pathway is obligatory for upregulation of CRE-modulated transcription, because it was completely blocked by infusion with the inhibitor U0126. ERK activation and CRE-mediated gene expression are downstream of cAMP signaling, because infusion with the cAMP inhibitory analog Rp-8-Cl-cAMPS attenuated both processes.

\section{Specificity of visually induced ERK activation}

Signaling through the ERK pathway is critical for synaptic plasticity (Sweatt, 2001), and it is essential for the shift of ocular dominance that occurs in the visual cortex after monocular deprivation (Di Cristo et al., 2001). In vitro experiments indicate that the ERK pathway acts as a sensor, translating electrical activ- 


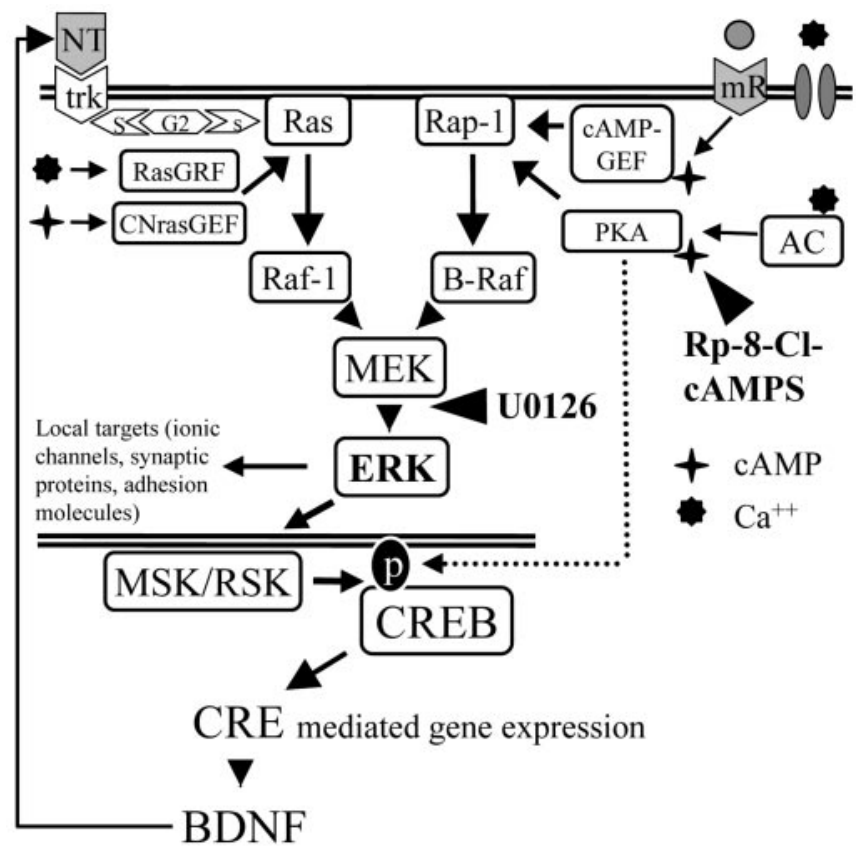

Figure 6. ERK pathway in the visual cortex. Neurotrophins and electrical activity modulate ERK through two separate pathways that converge on the ERK kinase MEK. The neurotrophin signal is conveyed from the tyrosine kinase receptors (trk) to Ras by the Shc-Grb2-sos intermediates (S-G2-s), leading to activation of ERK and CREB (Ginty et al., 1994; Pizzorusso et al., 2000). Electrical activity is translated in two different intracellular signals: (1) an increase of $\mathrm{Ca}^{2+}$ caused by influx through voltage-gated channels and NMDA receptors, and (2) an increase of CAMP attributable to activation of metabotropic receptors $(\mathrm{mR})$ or by (a-dependent adenylate cyclase (AD). The CAMP-dependent activation of ERK is mediated by CAMP-GEF and CNrasGEF, whereas the direct $\mathrm{Ca}$-dependent activation of ERK is primarily mediated by the Ca-dependent regulating factor RasGRF. The CRE promoter controls the expression of a large number of genes including BDNF (West et al., 2001). NT, Neurotrophins; AC, adenylate cyclase.

ity into varying degrees of ERK phosphorylation (English and Sweatt, 1996; Fields et al., 1997; Winder et al., 1999) through signaling that is regulated by activity-dependent modulation of the levels of $\mathrm{Ca}^{2+}$ influx and cAMP (Bading and Greenberg, 1991; Fiore et al., 1993; Impey et al., 1998, 1999). Similar mechanisms might also be operating in the brain of the behaving animal, but the relationship between physiological stimulation and ERK activation has been little investigated in vivo. We show that visually driven electrical activity brought about by exposure to normal visual environment after a brief period of darkness powerfully activated ERK in the visual cortex. ERK activation displayed remarkable spatial and temporal characteristics. Specifically, ERK activation was transient, peaking at $15 \mathrm{~min}$ after light exposure and returning to baseline within $40 \mathrm{~min}$, and it was maximal in layers II-III. Layer V cells and inhibitory interneurons, regardless of their cortical depth, were poorly responsive. A simple explanation of the spatially segregated activation of ERK might be the result of low levels of expression of ERK in the neuronal populations that were pERK negative. This interpretation seems unlikely, because a wide array of stimuli, including infusion with BDNF (Han and Holtzman, 2000), ischemia (Kitagawa et al., 1999), and epileptic seizure (Berkeley et al., 2002) induces widespread ERK activation in the cortex. A more attractive interpretation is that the levels of visually induced ERK phosphorylation are determined by the responsiveness of each neuronal class to visual stimulation. Indeed, the cells displaying the strongest visually induced ERK activation, such as layer II-III pyramids, are also the cells known to respond to visual stimuli with the highest spike rates (Gray and McCormick, 1996; Brumberg et al., 2000). In contrast, the large pyramidal cells of layer $\mathrm{V}$ and inhibitory interneurons respond to visual stimuli with a lowspiking frequency (Mason and Larkman, 1990; Azouz et al., 1997) and showed minimal ERK activation.

The importance of the pattern of incoming electrical activity for ERK induction is highlighted by the lack of ERK activation in animals exposed to light with bilateral eyelid suture, a condition in which visually driven electrical activity lacks the highfrequency spiking that is characteristic of pattern vision. This finding emphasizes the ability of ERK to respond specifically to the patterns of electrical activity that are essential for synapse stabilization during development. The presence of such a specificity of activation is also suggested by the lack of visually driven ERK activation in anesthetized rats. Indeed, anesthesia is known to prevent ocular dominance plasticity (Rauschecker and Hahn, 1987). Thus, ERK is likely to act as an early mediator of the action of visual experience on synaptic plasticity, primarily in neurons located in layers II-III, the layers in which experience-dependent cortical reorganization is initiated in a number of models of cortical plasticity (Buonomano and Merzenich, 1998; Feldman, 2000; Trachtenberg et al., 2000; Trachtenberg and Stryker, 2001).

\section{Visual experience uses the CAMP-PKA system and ERK to regulate CRE-mediated gene expression}

CREB is a calcium-activated transcription factor that regulates the expression of genes bearing a CRE promoter (Lonze and Ginty, 2002). CREB regulation of gene expression is important for plasticity in various brain structures (Silva et al., 1998). In particular, the introduction of a dominant negative form of CREB into visual cortical neurons blocks the effects of monocular deprivation (Mower et al., 2002), suggesting that the plastic rearrangements induced by monocular deprivation requires CREB action. Indeed, Pham et al. (1999) showed that CRE-mediated gene expression is activated in the visual cortex of monocularly deprived CRE-LacZ mice. However, monocular deprivation does not allow distinguishing between the direct regulation of CRE-mediated transcription by visual experience and the activation of CRE-mediated gene expression associated with the plasticity mechanisms elicited by the competitive interactions between the two eyes. We showed that visual experience sustained a basal level of CRE-mediated gene expression, and that $30 \mathrm{~min}$ of light exposure after Dr was sufficient to cause a dramatic episode of CRE-mediated gene expression that returned to control levels within several hours. As previously shown for ERK, visual stimulation through the sutured eyelids was not sufficient to activate CRE-mediated gene expression, underscoring the importance of patterned visual stimuli for activation of CRE-mediated transcription.

What are the cellular events that mediate the effects of visual experience on CRE-mediated gene expression? Studies on cultured neurons have shown that activation of CREB-mediated transcription by electrical activity relies on the activation of signaling pathways involving ERK, cAMP-PKA, and CaMKs (calmodulin-dependent protein kinase) (West et al., 2001; Deisseroth and Tsien, 2002). A major finding of this study is that physiological visual stimulation of cortical neurons in vivo requires ERK for initiation of CRE-mediated gene expression. Intriguingly, CRE-mediated transcription initially appears in superficial cortical layers, the same layers in which ERK is activated, but subsequently also becomes evident in the deep layers. It is conceivable that the initial episode of ERK phosphorylation might trigger the production and release of other molecular me- 
diators such as neurotrophins that, in conjunction with visually driven activity, could be responsible for spreading and maintaining CRE-mediated gene expression.

Inhibition of cAMP signaling by the analog Rp-8-Cl-cAMPS strongly reduced visually induced ERK phosphorylation. Increased levels of cAMP can cause ERK phosphorylation (Martin et al., 1997) by two different molecular pathways (Grewal et al., 1999). First, cAMP activates PKA that, in turn, activates the G-protein Rap1 (Vossler et al., 1997; York et al., 1998). Second, cAMP activates, independently of PKA, the Ras activator CNrasGEF (Pham et al., 2000) and the Rap1 activator Epac/cAMP-GEF (de Rooij et al., 1998; Kawasaki et al., 1998) with consequent activation of ERK (Grewal et al., 2000; Iida et al., 2001). Although PKA is certainly blocked by Rp-8-Cl-cAMPS, nothing is known about the action of this compound on molecules belonging to the PKA independent pathways. Even if the use of Rp-8-Cl-cAMPS does not allow a clear discrimination between these mechanisms, our data demonstrate that the cAMP-PKA system acts upstream of ERK to transduce visually driven activity.

Our data show that the infusion with Rp-8-Cl-cAMPS strongly attenuated CRE-mediated gene expression triggered by visual experience, demonstrating that the integrity of both the ERK and PKA pathways is required for proper long-lasting activation of CREB-dependent gene expression. The most economical interpretation of these data is that cAMP-PKA acts only upstream of ERK. In keeping with this possibility, previous studies showed that the PKA-dependent activation of ERK mediates the depolarization-induced initiation of the CRE-mediated gene expression in neuronal cultures (Impey et al., 1998). However, because the requirement for ERK activation could occur at a level downstream of CREB (Grewal et al., 2000), it cannot be excluded that PKA cooperates with ERK-dependent mechanisms at the level of the transcriptional complex of CRE-bearing genes to regulate gene expression.

Recent results demonstrate that the mutation of the autophosphorylation site of $\alpha$ CaMKII causes impairments in ocular dominance plasticity (Taha et al., 2002). Because $\alpha$ CaMKII contributes to ERK regulation (Chen et al., 1998; Kim et al., 2003), it is conceivable that its actions on ocular dominance plasticity might occur through ERK. In summary, our results indicate that ERK integrates the action of various signaling pathways (dependent and independent on PKA) activated by patterned visual stimuli and funnels this information to the transcription complex that regulates the expression of genes bearing a CRE promoter.

\section{References}

Azouz R, Gray CM, Nowak LG, McCormick DA (1997) Physiological properties of inhibitory interneurons in cat striate cortex. Cereb Cortex 7:534-545.

Bading H, Greenberg ME (1991) Stimulation of protein tyrosine phosphorylation by NMDA receptor activation. Science 253:912-914.

Barth AL, McKenna M, Glazewski S, Hill P, Impey S, Storm D, Fox K (2000) Upregulation of cAMP response element-mediated gene expression during experience-dependent plasticity in adult neocortex. J Neurosci 20:4206-4216.

Beaver CJ, Ji Q, Fischer QS, Daw NW (2001) Cyclic AMP-dependent protein kinase mediates ocular dominance shifts in cat visual cortex. Nat Neurosci 4:159-163.

Berkeley JL, Decker MJ, Levey AI (2002) The role of muscarinic acetylcholine receptor-mediated activation of extracellular signal-regulated kinase 1/2 in pilocarpine-induced seizures. J Neurochem 82:192-201.

Brumberg JC, Nowak LG, McCormick DA (2000) Ionic mechanisms underlying repetitive high-frequency burst firing in supragranular cortical neurons. J Neurosci 20:4829-4843.

Buonomano DV, Merzenich MM (1998) Cortical plasticity: from synapses to maps. Annu Rev Neurosci 21:149-186.
Chen HJ, Rojas-Soto M, Oguni A, Kennedy MB (1998) A synaptic RasGTPase activating protein (p135 SynGAP) inhibited by CaM kinase II. Neuron 20:895-904.

Christen WG, Mower GD (1987) Effects of monocular occlusion and diffusion on visual system development in the cat. Brain Res 415:233-241.

Dash PK, Karl KA, Colicos MA, Prywes R, Kandel ER (1991) cAMP response element-binding protein is activated by $\mathrm{Ca}^{2+} /$ calmodulin- as well as cAMP-dependent protein kinase. Proc Natl Acad Sci USA 88:5061-5065.

de Rooij J, Zwartkruis FJ, Verheijen MH, Cool RH, Nijman SM, Wittinghofer A, Bos JL (1998) Epac is a Rapl guanine-nucleotide-exchange factor directly activated by cyclic AMP. Nature 396:474-477.

Deisseroth K, Tsien RW (2002) Dynamic multiphosphorylation passwords for activity-dependent gene expression. Neuron 34:179-182.

Di Cristo G, Berardi N, Cancedda L, Pizzorusso T, Putignano E, Ratto GM, Maffei L (2001) Requirement of ERK activation for visual cortical plasticity. Science 292:2337-2340.

English JD, Sweatt JD (1996) Activation of p42 mitogen-activated protein kinase in hippocampal long term potentiation. J Biol Chem 271:24329-24332.

Feldman DE (2000) Timing-based LTP and LTD at vertical inputs to layer II/III pyramidal cells in rat barrel cortex. Neuron 27:45-56.

Fields RD, Eshete F, Stevens B, Itoh K (1997) Action potential-dependent regulation of gene expression: temporal specificity in $\mathrm{Ca}^{2+}$, cAMPresponsive element binding proteins, and mitogen-activated protein kinase signaling. J Neurosci 17:7252-7266.

Fiore RS, Murphy TH, Sanghera JS, Pelech SL, Baraban JM (1993) Activation of p42 mitogen-activated protein kinase by glutamate receptor stimulation in rat primary cortical cultures. J Neurochem 61:1626-1633.

Ginty DD, Bonni A, Greenberg ME (1994) Nerve growth factor activates a Ras-dependent protein kinase that stimulates c-fos transcription via phosphorylation of CREB. Cell 77:713-725.

Gray CM, McCormick DA (1996) Chattering cells: superficial pyramidal neurons contributing to the generation of synchronous oscillations in the visual cortex. Science 274:109-113.

Grewal SS, York RD, Stork PJ (1999) Extracellular-signal-regulated kinase signalling in neurons. Curr Opin Neurobiol 9:544-553.

Grewal SS, Fass DM, Yao H, Ellig CL, Goodman RH, Stork PJ (2000) Calcium and cAMP signals differentially regulate cAMP-responsive elementbinding protein function via a Rap1-extracellular signal-regulated kinase pathway. J Biol Chem 275:34433-34441.

Han BH, Holtzman DM (2000) BDNF protects the neonatal brain from hypoxic-ischemic injury in vivo via the ERK pathway. J Neurosci 20:5775-5781.

Hara K, Harris RA (2002) The anesthetic mechanism of urethane: the effects on neurotransmitter-gated ion channels. Anesth Analg 94:313-318.

Iida N, Namikawa K, Kiyama H, Ueno H, Nakamura S, Hattori S (2001) Requirement of Ras for the activation of mitogen-activated protein kinase by calcium influx, cAMP, and neurotrophin in hippocampal neurons. J Neurosci 21:6459-6466.

Impey S, Mark M, Villacres EC, Poser S, Chavkin C, Storm DR (1996) Induction of CRE-mediated gene expression by stimuli that generate longlasting LTP in area CA1 of the hippocampus. Neuron 16:973-982.

Impey S, Obrietan K, Wong ST, Poser S, Yano S, Wayman G, Deloulme JC, Chan G, Storm DR (1998) Cross talk between ERK and PKA is required for $\mathrm{Ca}^{2+}$ stimulation of CREB-dependent transcription and ERK nuclear translocation. Neuron 21:869-883.

Impey S, Obrietan K, Storm DR (1999) Making new connections: role of ERK/MAP kinase signaling in neuronal plasticity. Neuron 23:11-14.

Kawasaki H, Springett GM, Mochizuki N, Toki S, Nakaya M, Matsuda M, Housman DE, Graybiel AM (1998) A family of cAMP-binding proteins that directly activate Rap1. Science 282:2275-2279.

Kim JH, Lee HK, Takamiya K, Huganir RL (2003) The role of synaptic GTPase-activating protein in neuronal development and synaptic plasticity. J Neurosci 23:1119-1124.

Kitagawa H, Warita H, Sasaki C, Zhang WR, Sakai K, Shiro Y, Mitsumoto Y, Mori T, Abe K (1999) Immunoreactive Akt, PI3-K and ERK protein kinase expression in ischemic rat brain. Neurosci Lett 274:45-48.

Lonze BE, Ginty DD (2002) Function and regulation of CREB family transcription factors in the nervous system. Neuron 35:605-623.

Martin KC, Michael D, Rose JC, Barad M, Casadio A, Zhu H, Kandel ER 
(1997) MAP kinase translocates into the nucleus of the presynaptic cell and is required for long-term facilitation in Aplysia. Neuron 18:899-912.

Mason A, Larkman A (1990) Correlations between morphology and electrophysiology of pyramidal neurons in slices of rat visual cortex. II. Electrophysiology. J Neurosci 10:1415-1428.

Movshon JA, Eggers HM, Gizzi MS, Hendrickson AE, Kiorpes L, Boothe RG (1987) Effects of early unilateral blur on the macaque's visual system. III. Physiological observations. J Neurosci 7:1340-1351.

Mower AF, Liao DS, Nestler EJ, Neve RL, Ramoa AS (2002) cAMP/Ca ${ }^{2+}$ response element-binding protein function is essential for ocular dominance plasticity. J Neurosci 22:2237-2245.

Pham N, Cheglakov I, Koch CA, de Hoog CL, Moran MF, Rotin D (2000) The guanine nucleotide exchange factor CNrasGEF activates ras in response to cAMP and cGMP. Curr Biol 10:555-558.

Pham TA, Impey S, Storm DR, Stryker MP (1999) CRE-mediated gene transcription in neocortical neuronal plasticity during the developmental critical period. Neuron 22:63-72.

Pizzorusso T, Ratto GM, Putignano E, Maffei L (2000) Brain-derived neurotrophic factor causes cAMP response element-binding protein phosphorylation in absence of calcium increases in slices and cultured neurons from rat visual cortex. J Neurosci 20:2809-2816.

Rauschecker JP, Hahn S (1987) Ketamine-xylazine anaesthesia blocks consolidation of ocular dominance changes in kitten visual cortex. Nature 326:183-185.

Roberson ED, English JD, Adams JP, Selcher JC, Kondratick C, Sweatt JD (1999) The mitogen-activated protein kinase cascade couples PKA and PKC to cAMP response element binding protein phosphorylation in area CA1 of hippocampus. J Neurosci 19:4337-4348.
Silva AJ, Kogan JH, Frankland PW, Kida S (1998) CREB and memory. Annu Rev Neurosci 21:127-148.

Sweatt JD (2001) The neuronal MAP kinase cascade: a biochemical signal integration system subserving synaptic plasticity and memory. J Neurochem 76:1-10.

Taha S, Hanover JL, Silva AJ, Stryker MP (2002) Autophosphorylation of alphaCaMKII is required for ocular dominance plasticity. Neuron 36:483-491.

Trachtenberg JT, Stryker MP (2001) Rapid anatomical plasticity of horizontal connections in the developing visual cortex. J Neurosci 21:3476-3482.

Trachtenberg JT, Trepel C, Stryker MP (2000) Rapid extragranular plasticity in the absence of thalamocortical plasticity in the developing primary visual cortex. Science 287:2029-2032.

Vossler MR, Yao H, York RD, Pan MG, Rim CS, Stork PJ (1997) cAMP activates MAP kinase and Elk-1 through a B-Raf- and Rap1-dependent pathway. Cell 89:73-82.

West AE, Chen WG, Dalva MB, Dolmetsch RE, Kornhauser JM, Shaywitz AJ, Takasu MA, Tao X, Greenberg ME (2001) Calcium regulation of neuronal gene expression. Proc Natl Acad Sci USA 98:11024-11031.

Wiesel TN, Hubel DH (1965) Comparison of the effects of unilateral and bilateral eye closure on cortical unit responses in kittens. J Neurophysiol 28:1029-1040.

Winder DG, Martin KC, Muzzio IA, Rohrer D, Chruscinski A, Kobilka B, Kandel ER (1999) ERK plays a regulatory role in induction of LTP by theta frequency stimulation and its modulation by beta-adrenergic receptors. Neuron 24:715-726.

York RD, Yao H, Dillon T, Ellig CL, Eckert SP, McCleskey EW, Stork PJ (1998) Rap1 mediates sustained MAP kinase activation induced by nerve growth factor. Nature 392:622-626. 